ELECTRONIC LETTER

\title{
Prader-Willi syndrome: the psychopathological phenotype in uniparental disomy
}

W M A Verhoeven, S Tuinier, L M G Curfs

J Med Genet 2003;40:el 12 (http://www.jmedgenet.com/cgi/content/full/40/10/el12)

$P$ rader-Willi syndrome (PWS) is a neurogenetic disorder resulting from the absence of a normal paternal contribution to the chromosome 15 q11-13 region. The clinical manifestations of PWS are: reduced fetal activity during pregnancy, a transient severe hypotonia and feeding problems in the neonatal period, a variable degree of mental retardation, hyperphagia, obsessive compulsive features such as skin picking, and a variety of hypothalamic dysfunctions. The latter become manifest as hypogonadism, short stature, sleep disturbances, and defects in temperature regulation. In addition, post mortem studies reveal a significantly lower number of small oxytocin secreting neurones in the paraventricular hypothalamus and, in some cases, a reduction of vasopressin secreting neurones as well as diminished vasopressin precursor processing. ${ }^{12}$

Apart from the behavioural problems associated with food seeking and intellectual disability per se, PWS carries the risk of obsessive compulsive disorder, mood abnormalities and psychotic disorders..$^{3-5}$ Given the high prevalence of these psychiatric symptoms, ${ }^{6}$ the term psychopathological phenotype is justified. ${ }^{7}$

\section{METHODS AND RESULTS}

Over the past seven years, 23 PWS patients (mean age 31 years) were referred for neuropsychiatric evaluation because of long lasting or recurrent behavioural problems and psychotic symptoms (mean age at onset 24 years). Part of the data on these patients was published previously. ${ }^{4}$ In all patients, a standard psychiatric examination was performed and additional data on the history and course of the condition were collected from all available sources. Tentative formal psychiatric diagnoses were established according to the clinical descriptions and diagnostic guidelines of the ICD10. ${ }^{9}$ All but two patients (insufficient data in the medical record) had a history of mood instability paralleled by fluctuating behavioural problems. With respect to actual psychopathology, five patients met the criteria for a bipolar affective disorder, in that they showed an episodic pattern of euphoria, hyperactivity, and sleep disturbances, or depressed

Table 1 Characteristics of 18 PWS patients with relapsing atypical psychosis

\begin{tabular}{lcc}
\hline Symptoms and course & Number & $\%$ \\
\hline Auditory hallucinations & 9 & 50 \\
Perceptual disturbances & 4 & 12 \\
Paranoid ideation & 14 & 78 \\
Confusion & 16 & 89 \\
Anxieties & 17 & 94 \\
Mood swings & 18 & 100 \\
Emotional turmoil & 15 & 83 \\
Obsessive rituals $\uparrow$ & 15 & 83 \\
Hyperactivity/agitation & 10 & 56 \\
Subacute onset & 18 & 100 \\
\hline
\end{tabular}

\section{Key points}

- Prader-Willi syndrome (PWS) is a neurogenetic disorder resulting from the absence of a normal paternal contribution to the chromosome 15q11-13 region.

- A number of physical and psychiatric symptoms present in the disease, thus the term psychopathological phenotype is justified.

- We examined 23 PWS patients with behavioural and psychotic problems. In five patients, a diagnosis of bipolar affective disorder was established while 18 met the criteria of a cycloid psychosis. Most patients could be treated successfully with one or a combination of mood stabilisers.

- Genetically, 14 of the patients had a uniparental disomy, and two patients had a paternal deletion. Nearly all had a history of long lasting mood instability.

- It is concluded that PWS caused by UPD is associated with psychotic deterioration and that the psychopathological phenotype includes disorders from the bipolar affective spectrum that warrant treatment with mood stabilisers.

mood and inactivity. In the other 18 patients, the psychiatric symptomatology included emotional turmoil, anxieties, irritability, confusion, (rapid) mood swings, hallucinatory experiences, and paranoid ideation, with a variable intensity and sub-acute onset. Therefore, a diagnosis of cycloid psychosis was considered most appropriate (table 1). Treatment with one or a combination of mood stabilisers such as lithium (0-8 mmol/l), and/or valproic acid $(60 \mathrm{mg} / \mathrm{l})$, resulted in a full recovery and prevention of relapses of both psychotic episodes and mood and behavioural instability. Concerning the genetic aetiology, two patients had a paternal deletion. In seven patients, a clinical diagnosis was made and of these, three were genetically confirmed but not differentiated. In the remaining 14 patients a uniparental disomy (UPD) was demonstrated. The main characteristics of the patients are presented in table 2 .

\section{DISCUSSION}

In a population of PWS patients the expected percentage of deletions and UPD is about 75 and 25 respectively, ${ }^{10}$ whereas in the present group, excluding those with a clinical diagnosis, percentages of 12.5 and 87.5 were found. These

Abbreviations: PWS, Prader-Willi syndrome; UPD, uniparental disomy 


\begin{tabular}{|c|c|c|c|c|c|}
\hline Number & Sex & Age & $\begin{array}{l}\text { Level of mental } \\
\text { retardation }\end{array}$ & $\begin{array}{l}\text { Age at onset } \\
\text { (years) }\end{array}$ & Genetics \\
\hline \multicolumn{6}{|c|}{ Cycloid psychosis } \\
\hline 1 & M & 29 & Severe & 17 & UPD \\
\hline 2 & $M$ & 35 & Severe & 25 & UPD \\
\hline 3 & M & 30 & Severe & 25 & UPD \\
\hline 4 & $M$ & 41 & Mild & 40 & Confirmed \\
\hline 5 & M & 38 & Moderate & 16 & UPD \\
\hline 6 & $M$ & 34 & Moderate & 18 & Deletion \\
\hline 7 & $\mathrm{~F}$ & 20 & Mild & 20 & UPD \\
\hline 8 & $\mathrm{~F}$ & 34 & Mild & 21 & Clinical \\
\hline 9 & $\mathrm{~F}$ & 35 & Mild & 34 & UPD \\
\hline 10 & $\mathrm{~F}$ & 37 & Mild & 20 & UPD \\
\hline 11 & M & 17 & Mild & 17 & Clinical \\
\hline 12 & $M$ & 30 & Mild & 30 & UPD \\
\hline 13 & $\mathrm{~F}$ & 19 & Mild & 19 & UPD \\
\hline 14 & $\mathrm{~F}$ & 43 & Mild & 34 & UPD \\
\hline 15 & $M$ & 20 & Mild & 19 & Clinical \\
\hline 16 & $M$ & 38 & Moderate & 23 & UPD \\
\hline 17 & $\mathrm{~F}$ & 19 & Mild & 19 & UPD \\
\hline 18 & $\mathrm{~F}$ & 36 & Mild & 24 & Confirmed \\
\hline \multicolumn{6}{|c|}{ Bipolar affective disorder } \\
\hline 19 & $\mathrm{~F}$ & 33 & Moderate & 23 & UPD \\
\hline 20 & $\mathrm{~F}$ & 42 & Moderate & 25 & UPD \\
\hline 21 & M & 38 & Mild & 32 & Clinical \\
\hline 22 & $\mathrm{~F}$ & 26 & Moderate & 26 & Deletion \\
\hline 23 & $\mathrm{~F}$ & 23 & Mild & 21 & Confirmed \\
\hline
\end{tabular}

results indicate an association between UPD and psychotic illness that is confirmed by two other recent reports. ${ }^{11}{ }^{12}$

Focussing on the cross-sectional diagnosis of psychopathology, however, may conceal the history of affective instability in these patients. Descriptions of so-called instability of mood and behaviour in patients with intellectual disabilities have been published since the beginning of the last century, and meet, depending on the presence of mood elevation, the criteria of either cyclothymia or unstable mood disorder. ${ }^{13}$ As affective symptoms are frequently expressed as mood swings, irritability, impulsivity, aggression, and self injury, a diagnosis of depression is often overlooked. ${ }^{14}$ Although the literature on psychopathology in PWS refers frequently to affective symptoms, there is no information about the lifetime prevalence of affective disorders in this syndrome.

In the patients reported here, the psychosis was characterised by symptoms such as confusion, auditory hallucinations, and paranoid behaviour on the one hand and an increase in obsessive rituals, anxieties, and mood swings on the other, and was preceded by affective instability for many years. Although the actual psychopathology justifies a diagnosis of cycloid psychosis, longitudinal evaluation points towards an atypical bipolar disorder. It can therefore be hypothesised that the psychopathological phenotype of PWS patients with an UPD aetiology also comprises an increased risk for a bipolar affective disorder. In these patients, signs of cyclothymia or unstable mood disorder should be treated with mood stabilisers in order to prevent psychotic deterioration. This difference in the psychopathological phenotype between patients with a paternal deletion and UPD is intriguing and clinically relevant, and may indicate that imprinted genes outside the typically deleted region on the paternal or the maternal chromosome may contribute to the psychopathological phenotype. ${ }^{10}$

\section{CONCLUSION}

In the present study, 23 PWS patients were evaluated for psychiatric symptoms. The genetic aetiology was a paternal deletion in two patients and an uniparental disomy (UPD) in
14 patients. In five patients, a diagnosis of bipolar affective disorder was established while 18 met the criteria for a cycloid psychosis. Nearly all had a history of long lasting mood instability.

It is concluded that PWS caused by UPD is associated with psychotic deterioration and that the psychopathological phenotype includes disorders from the bipolar affective spectrum that warrant treatment with mood stabilisers.

\section{Authors' affiliations}

W M A Verhoeven, S Tuinier, Vincent van Gogh Institute for Psychiatry, Venray, The Netherlands

W M A Verhoeven, Department of Psychiatry, Erasmus University Medical Centre, Rotterdam, The Netherlands

L M G Curfs, Clinical Genetics Department, University Maastricht, The Netherlands

Correspondence to: Professor Dr W M A Verhoeven, Vincent van Gogh Institute for Psychiatry, Stationsweg 46, 5803 AC Venray, The Netherlands; wverhoeven@vvgi.nl

\section{REFERENCES}

1 Gabreëls BA, Swaab DF, Seidah NG, van Duijnhoven HL, Martens GJ, van Leeuwen FW. Differential expression of the neuroendocrine polypeptide 7B2m in hypothalami of Prader-(Labhart)-Willi syndrome patients. Brain Res 1994;657:281-93.

2 Gabreëls BA, Swaab DF, de Kleijn DP, Seidah NG, Van de Loo JW, Van de Ven WJ, Martens GJ, van Leeuwen FW. Attenuation of the polypeptide 7B2m prohormone convertase PC2 and vasopressin in the hypothalamus of some Prader-Willi patients: Indications for a processing defect. J Clin Endocrinol Metab 1998:83:591-9.

3 Clarke DF. Prader-Willi syndrome and psychoses. Br J Psychiatry 1993:163:680-4

4 Verhoeven WMA, Curfs LMG, Tuinier S. Prader-Willi syndrome and cycloid psychosis. J Intellect Disabil Res 1998:42:455-62.

5 Descheemaeker MJ, Vogels A, Govers V, Borghgraef M, Willekens D, Swillen A, Verhoeven W, Fryns JP. Prader-Willi syndrome: new insights in the behavioural and psychiatric spectrum. J Intellect Disabil Res 2002;46:41-50.

6 Cassidy SB. Prader-Willi syndrome. In: Cassidy SB, Allanson JE, eds. Management of genetic syndromes. New York: Wiley-Liss, Inc., Publication, 2001:301-23.

7 Verhoeven WMA, Tuinier S, Curfs LMG. Prader-Willi psychiatric syndrome and Velo-Cardio-Facial psychiatric syndrome. Genet Couns 2000;11:205-13. 
8 Verhoeven WMA, Tuinier S, Curfs LMG. Prader-Willi syndrome: cycloid psychosis in a genetic subtype. Acta Neuropsychiatr 2003;15:23-7.

9 World Health Organization. The ICD-10 classification of mental and behavioural disorders. Geneva: WHO, 1992.

10 Vogels A, Fryns JP. The Prader-Willi syndrome and the Angelman syndrome. Genet Couns 2002;13:385-96.

11 Boer H, Holland A, Whittington J, Butler J, Webb T, Clarke D. Psychotic illness in people with Prader-Willi syndrome due to chromosome 15 maternal uniparental disomy. The Lancet 2002;359:135-6.
12 Vogels A, Matthiis G, Legius E, Devriendt K, Fryns JP. Chromosome 15 maternal uniparental disomy and psychosis in Prader-Willi syndrome. J Med Genet 2003;40:72-3

13 Verhoeven WMA, Tuinier S. Cyclothymia or unstable mood disorder? A systematic treatment evaluation with valproic acid. J Appl Res Intellect Disabil 2001;14:147-154.

14 Verhoeven WMA, Sijben AES, Tuinier S. Psychiatric consultation in intellectual disability: dimensions, domains and vulnerability. Eur J Psychiatr in press. 